\title{
Relationships between Psychological Resilience and Work Engagement: Field Study in the Geography of Tragedies; Afghanistan Universities
}

\author{
Olcay Okun \\ Hasan Kalyoncu University, Turkey \\ Korhan Arun \\ Namik Kemal University, Tekirdag, Turkey
}

\begin{abstract}
Psychological resilience has been, to a certain extent, explained by Western individualistic, and static factors. However, dynamic factors that affect the resilience through the process are proofed to be more important, i.e. culture. In some collectivist nations, like Afghanistan, the meaning of work embedded in what their own culture taught them. Afghan cultural context may provide the foundation for different ways of knowing, including resilience, by people in that nation. So, the main aim of this research is to find out the impact of psychological resilience on work engagement from the Afghan national cultural perspective. In a study of 713 staffs from 27 universities in Afghanistan show that work engagement dimensions are more related to the social and family factor of resilience than individual ones, supporting the cultural cohesion theory of individuals of Afghan people. Resiliency and energy are also one of the critical components of work engagement, vitality as a more individualistic work engagement factor lost its importance.
\end{abstract}

Keywords: psychological resilience, resilience, work engagement, Afghan universities

Afghan people, even if after many years of war, has gained strength from exposure to the stressful environment. Although certain stable factors like biological predispositions (de Terte, Becker, \& Stephens, 2009) may help Afghan peoples' resilience, they are not competent at the individual level (Charmes, 2019; Wachs, 2012) rather dynamic psychological factors are more significant (Baumeister \& Vohs, 2007; Bonanno \& Diminich, 2013; Killgor, Taylor, Cloonan \& Dailey, 2020). These dynamic factors like social support, adaptive health practices are more important than individual ones because the systematic cultural differences are related to domain-specific mental constructs (Kashima, 2013). As a result, social networks as context are not just contingent on outcome of resilience but part of resilience itself (Lee, Nam, Kim, Kim, Lee, \& Lee, 2013; Vella \& Pai, 2019). One of the outcomes of resilience is coping with job stressors and removing barriers on their

Correspondence concerning this article should be addressed to Dr. Korhan li, Associate Professor, Namik Kemal University Faculty of Economics and Administrative Sciences, Tekirdag, Turkey, Email:korhanarun@gmail.com

Contribution of Authors:

1. Olcay Okun made contributions by conceiving and designing analysis, collecting data, and writing paper.

2. Korhan Arun made contributions by conceiving, designing and performing analysis, and writing paper. 
way to achieving goals and, thus, engagement at work (Gagné, 2014). Features of the broader context are likely to shape how engagement is experienced (Johns, 2006) by internalized culture and values (Sheldon, 2002) because they define what work is meaningful (Meyer, 2014). In a nutshell, the main aim of this paper is research on how resilience can be related to context rather than individual psychology can also affect the coping process at work, resulting in engagement.

Resilience has been examined across a range of contexts (Fletcher \& Sarkar, 2013), but neither context captivated the importance of cultural differences, especially at the national level. Even if studies have examined the emergence and developmental consequences of resilience in cultural contexts (Feldman \& Masalha, 2007), their approach were descriptive rather than prescriptive. Literature need prescriptive theories specify what individuals must do to become resilient, and they should identify any necessary conditions for using a particular type of behavior effectively. Additionally, domain-general constructs of Western resilience definitions are causally implicated in domain-specific psychological processes at the national levels. Even if some authors discussed that resilience could be developed by exposure to risk or adversity (Rutter, 2006), understanding the process through which individuals overcome the adversities in different cultures is one of the main difficulties in researching resilience outcomes. So, operationalizing the outcomes of resilience in Afghanistan, one of the toughest countries on earth, as context and a base of hardest risk factors in work engagement are tantalizingly important.

Afghanistan war has lasted more than 30 years based upon the interests of international powers, the poverty that followed. The ignorance that was intended to be imposed upon the people of Afghanistan, the religious strife among the people, made life difficult and harsh in Afghanistan (Fevzi, 2015). In Afghanistan, struggling with instability, deprivation and associated corruption constitute an existential and strategic threat (Jensen, 2019). Despite these absences, the country has never surrendered. Since they do not have any financial resources, strength, perseverance, and recovery when encountering adversity (Linnenluecke, 2017) should be sought in psychological resilience. As a result of wars and tragedies, little is known about adults' ability to stay healthy, work without symptoms, and resilience of people (Zolkoski \& Bullock, 2012). In other words, despite the negative experiences, the Afghan People are standing upright. Psychological resilience, a magical capacity in the geography of tragedies, was chosen as our research topic.

To think that individuals with high psychological resilience in the face of difficulties have extraordinary qualities without out of cultural context is not realistic. Resiliency can differ as a universal capacity depending on personality styles, demographic characteristics, individual strengths, and cultural differences (Newman, 2003). However, these common resilience factors, summarized under the global culture concepts, cultural coherence, and cultural causation models of the standard model of cultural, psychological theory, explains the systematic cultural differences found on domainspecific mental constructs (Arun, Şen, \& Okun, 2020; Arun \& Kahraman Gedik, 2020; Kashima, 2013).

The research will contribute to literature in fourth way. First, whether the dimensions of the concept can be conceived as relative and contextualized contrary to being global. Second, to clear the factors that help to foster resilience when it was not naturally occurring. Third, we find out if resilience is a multi-level phenomenon that operates within the interaction of these systems, namely whether resilience is a group level rather than an individual level. Moreover, lastly, we researched how resilience affects work engagement. 
Our study was conducted on academic and administrative staff working at 27 universities in Kabul, the capital of Afghanistan. The more specific research questions are:

Research Question 1: Is the psychological resilience both relative and contextualized of those working in Afghanistan Universities?

Research Question 2: How is the psychological resilience of those working in Afghanistan Universities affecting work engagement?

\section{Resilience}

Early literature related resilience to individuals' ability or character (Luthans, 2002; Rutter, 1987), but resilience is deeply entrenched to culture (Davies \& Thomas, 2003). As a result, a multidisciplinary approach to theory building of resilience needs a polycontextualization view (Tsui, Nifadkar \& Ou, 2009).

Eastern and Western kinds of domain-specific psychological constructs that differentiate Eastern and Western cultures exist in any given person, but their amounts different (Theron, Ann Cameron, Didkowsky, Liebenberg \& Ungar, 2011). However, differences in cultures are intertwined in historical and social narratives that give them meaning (Begeç \& Arun, 2020; Harrington, 2008). Different than the individual difference in the specific cultural context, the semiotic cultural model focuses on the difference between the distribution of specific individualistic and collectivistic acts (Arun \& Gedik, 2020; Kashima, 2013; Nakkula, Foster, Mannes, \& Bolstrom, 2010). The orientation of resilience can be different between cultural groups rather than individual differences. Expression of underlying cultural value emphasizes the policies, practices, and expectations differently at national cultural groups (Schwartz, 2009).

When resilience is defined as an interactive concept of individual and environmental interaction than the outcome is relative to the combination of experiences and social ecological understanding (Rutter, 2006; Ungar, 2011). So, there should be macro-level cultural differences, and micro-level domain-specific psychological resilience factors according to the standard model and the semiotic model. Kabul American University academic staffs identified Afghan students with the concepts of "resilience, pride and a great desire to learn and progress" when asked to compare them with their American counterparts (Baehr, 2009).

Friborg et al., (2005) defined a six-dimensional structure of resilience: perception about the future, self-perception, social competence, family cohesion, structured style, and social resources (Friborg et al., 2005). In our study, this six-dimensional structure was used.

\section{Work Engagement}

Work engagement is a multidimensional structure defined as a positive, satisfying, workrelated state of mind characterized by, vitality, dedication, and absorption (Schaufeli, Bakker, \& Salanova, 2006; Schaufeli, Salanova, González-romá, \& Bakker, 2002). Vitality is characterized by a high level of energy and mental flexibility while working, the desire to exert work and stability even in the face of difficulties. Dedication is characterized by feeling important, enthusiasm, inspiration, pride, and a sense of a challenge. Finally, absorption is characterized by a complete concentration of the person's work and to work happily so that time passes quickly, and the person has difficulty separating himself from work (González-Romá, Schaufeli, Bakker, \& Lloret, 2006; Ouweneel, Le Blanc, \& Schaufeli, 2013; Schaufeli, Bakker, \& Salanova, 2006).

Bailey, Madden, Thompson, and Kerridge (2019) reviewed the engagement literature and found five antecedents. First of the engagement antecedent is related to the psychological state of 
the individual (Kahn, 1990). The second antecedent is job-design-related factors that were explained by the job demands-resources (JD-R) framework (Park, Kim, Park, \& Lim, 2018). Perceived leadership and management are the third antecedents in their research paper; however, results have negative and positive relations. The fourth antecedent is about individual perceptions of organizational and team factors that can be grouped under social exchange theory (Cropanzano \& Mitchell, 2005). Lastly, Organizational interventions or activities are found as an antecedent of engagement that can be based on the broaden-and-build theory, which also explains resilience (Denovan \& Macaskill, 2017).

\section{Hypotheses Development}

Social identity theory presents a solid framework to understand the impact of resilience on work engagement. Resilience develops under the social-psychological factor and continues its evolution within the natural flow of life within the social structure, social inequalities, social processes, and social expectations. Increasing social support and social identity increases psychological resilience (Bottrell, 2009; Haslam et al., 2005).

Broaden-and-build theory suggests that positive psychological resources can be useful to work (Fredrickson, 2001). In this conceptual framework, while the administrative and academic staff's research in Afghanistan Kabul universities faces all the difficulties brought by life and work with their psychological resilience, their engagement to their jobs also increases. Knight, Patterson, and Dawson (2017) found that work engagement success is not affected by the focus of individual, job, training, and health-promoting interventions. They connected this phenomenon to indirect effects and mentioned the effect and style of intervention due to content. So, we can assume that style of intervention can be relative to a cultural context, specifically national culture. Although American and Soviet education models have been imposed on Kabul University since the 1960s, the resistance of Kabul University has weakened the cultural effects on both countries. Despite significant transformations in the structure, management device, and content of the disciplines, both superpowers could not change the traditions and values of professors and students. It has been proven that the university community is the main reason for any reforms brought to a university by external forces to succeed or fail (Tsvetkova, 2017).

According to self-determination theory, members of Afghan universities may not enjoy their job or see it as particularly meaningful, but quite as a means to attain desired outcomes controlled mainly by others- experience a sense of controlled regulation (Meyer et al., 2010; Meyer, 2014). Explorations to post-war conditions did not minimize the suffering of individuals to a degree; they created an empathic environment where academics learned to build bonds of attachment and repairing impaired resilience skills (Kass, 2017). So, many organizations operate inside just one country that we cannot ignore that country's values and culture as an influence on them (Bowles, 2014). 
Table 1

Relations of dimensions of the concepts

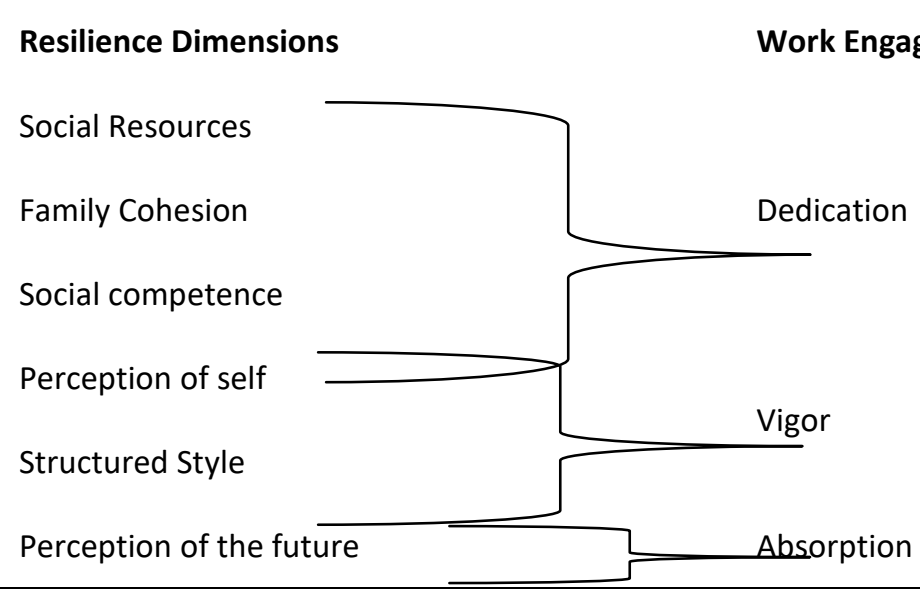

Hypothesis 1: Social and cultural related dimensions of resilience positively affect work engagement dimensions.

Many researchers studied engagement from an individual perspective of being engaged (Kahn, 1990; Saks, 2006; Schaufeli, Bakker, \& Van Rhenen, 2009; Swanberg, McKechnie, Ojha, \& James, 2011). Bandura's social cognitive theory (Bandura, 1997; McLellan et al., 2011) and is defined as a person's sense of being able to accomplish a particular task in a specific situation. However, there is no overarching definition or conceptualization (Bailey et al., 2013, 2019). If we assume that individual antecedents are important both in resilience and engagement (Table 1), then the second hypothesis is:

Hypothesis 2: Individual related dimensions of resilience positively affect work engagement dimensions.

\section{Method}

\section{Sample}

In the research, a survey, one of the primary data collection methods, was used. Between April 03, 2019, and September 28, 2019, all 713 academic and administrative staff working in 27 universities in Kabul, Afghanistan's Capital, were reached, and data of 251 staff were found suitable for analysis. The sample consists of 63 administrative and 188 academic staff. Since the sample is taken from Afghanistan, the proportion of women is below 10 percent with 17 people.

\section{Data Collection Tools}

The survey consists of three parts. In the first part, there are 33 questions about psychological resilience. In the second part, there are 17 questions about work engagement. In the third part, there are questions about demographic variables. In the research, the Resilience Scale for Adults scale, which was developed by Friborg et al. (2005), which aims to determine what are the main protective factors in regaining and maintaining mental health, was used. Personal strength/Perception of self-dimension include six questions e.g. "When something unforeseen happens I always find a solution/ I often feel bewildered", Personal strength /Perception of future dimension include four questions like "My plans for the future are difficult to accomplish", Structured 
style dimension has four questions e.g., "When I start on new things/projects I rarely plan ahead, just get on with it", Social competence dimension has six questions e.g., "Meeting new people is difficult for me/ something I am good at", Family cohesion dimension has six questions including "In my family we like to do things on our own/ do things together", and Social resources dimension includes seven questions e.g., "The bonds among my friends is weak/strong".

Work engagement was measured by the scale developed by Schaufeli et al., was used (Schaufeli, Bakker, \& Salanova, 2006). It has three dimensions: vigor, dedication, and absorption. Vigor dimension has six questions e.g, "At my work, I feel bursting with energy", dedication dimension includes five questions e.g., "I find the work that I do full of meaning and purpose", absorption dimension has six question e.g., "It is difficult to detach myself from my job". The validity and reliability of the scales were tested in Daria language, which was spoken in Afghanistan by Afghan academic staff from both scales in their original language, English, and the pilot application was translated, and then the scale was applied in Daria language. In the research of Friborg, Barlaug, Martinussen, Rosenvinge, and Hjemdal (2005), a low future orientation dimension is assessed with personal strength, and due to low reliability, it is removed from further analysis.

Validity and reliability analyses were performed in the western culture societies (Belgium, Canada, France, etc.), the original of the engagement scale. Besides, in the scale used for measurement, Schaufeli, Bakker, and Salanova (2006) have passed the goodness of fit tests for both one dimension and the dimensions of vitality, dedication, and absorption. Although the results of the goodness of fit for three dimensions are partially better, it is understood that it is suitable for the goodness of fit tests on a one-dimensional scale. In this article, explanatory and confirmatory factor analyzes were made again since there is a dilemma in both western culture and different dimensions.

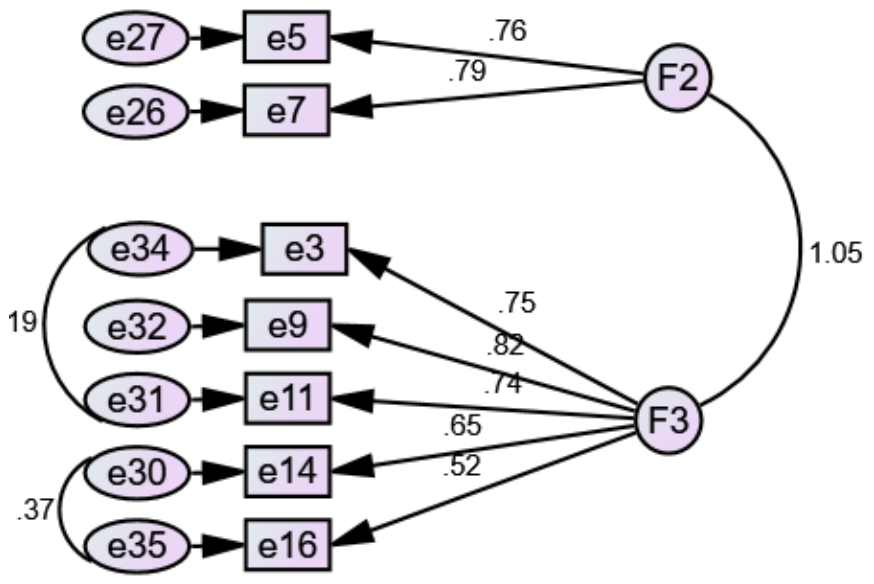

Figure 1: CFA of the Engagement Scale

As a result of CFA analyzes, three dimensions in the work engagement scale were expressed as two dimensions. The first dimension is "dedication" and the second dimension are the one that covers "absorption" questions except for one question (Question 3) (Figure 1). Goodness tests according to the structural equation model with AMOS are between CMIN / DF 1.864, GFI 0.978, and 
AGFI 0.944, RMSEA 0.59, respectively. In this respect, compliance and goodness tests of structural equation modeling for engagement provide the desired criteria.

\section{Table 2}

Descriptive Statistics

\begin{tabular}{lcccccc}
\hline & $\mathrm{N}$ & Minimum & Maximum & Mean & Std. Deviation & Variance \\
\hline Dedication & 251 & 1.00 & 7.00 & 5.2530 & 1.32316 & 1.751 \\
Absorption & 251 & 1.80 & 7.00 & 5.1920 & 1.13177 & 1.281 \\
Personal Perception & 251 & 1.33 & 5.00 & 3.0749 & .44818 & .201 \\
Structured Style & 251 & 1.00 & 5.00 & 3.0269 & .69823 & .488 \\
Social Competence & 251 & 1.00 & 5.00 & 3.1899 & .62219 & .387 \\
Family Cohesion & 251 & 1.00 & 5.00 & 3.2112 & .60343 & .364 \\
Social Resources & 251 & 1.00 & 5.00 & 3.0973 & .49984 & .250 \\
\hline
\end{tabular}

Descriptive statistics (Table 2) show that the engagement of the participants is very high. In both engagement measurements, the mean is higher than five. Resilience dimensions means are around 3, but their standard deviation is around 0.5 .

\section{Table 3}

Correlation Matrix Between Variables

\begin{tabular}{|c|c|c|c|c|c|c|c|c|}
\hline & & 1 & 2 & 3 & 4 & 5 & 6 & 7 \\
\hline 1. Dedication & & 1 & & & & & & \\
\hline 2. Absorption & & $.796^{* *}$ & 1 & & & & & \\
\hline 3. Personal & & .009 & .002 & 1 & & & & \\
\hline Strength & & & & & & & & \\
\hline $\begin{array}{l}\text { 4. Structured } \\
\text { Style }\end{array}$ & & .088 & .098 & $.246^{* *}$ & 1 & & & \\
\hline $\begin{array}{l}\text { 5. Social } \\
\text { Competence }\end{array}$ & $\begin{array}{l}\text { Pearson } \\
\text { Correlation }\end{array}$ & $.236^{* *}$ & $.132^{*}$ & $.230^{* *}$ & $.137^{*}$ & 1 & & \\
\hline $\begin{array}{l}\text { 6. Family } \\
\text { Cohesion }\end{array}$ & & $.330^{* *}$ & $.373^{* *}$ & .081 & $.235^{* *}$ & .017 & 1 & \\
\hline $\begin{array}{l}\text { 7. Social } \\
\text { Resources }\end{array}$ & & $.147^{*}$ & $.143^{*}$ & $.162^{*}$ & $.130^{*}$ & .108 & $.234^{* *}$ & 1 \\
\hline
\end{tabular}

$* \mathrm{p}<0.05, * * \mathrm{p}<0.01, * * * \mathrm{p}<0.001$

According to the results of the correlation analysis (Table 3), the social competence, family cohesion, and social resources dimensions of psychological resilience increase the "dedication" and "absorption" dimensions of the work engagement.

Multivariate analysis of variance (MANOVA) showed that the sample sizes in each group are approximately equal, it can be concluded that the results are robust, that is, reliable. 
Table 4

Multivariate Test Results

\begin{tabular}{|c|c|c|c|c|c|c|c|c|}
\hline Effect & & Value & $\mathrm{F}$ & $\begin{array}{l}\text { Hypothesis } \\
\text { df }\end{array}$ & $\begin{array}{c}\text { Error } \\
\text { df }\end{array}$ & Sig. & $\begin{array}{c}\text { Partial } \\
\text { Eta } \\
\text { Squared }\end{array}$ & $\begin{array}{l}\text { Observed } \\
\text { Power }^{d}\end{array}$ \\
\hline \multirow[t]{2}{*}{ Intercept } & $\begin{array}{l}\text { Pillai's } \\
\text { Trace }\end{array}$ & .996 & $3625.444^{b}$ & 2.000 & 26.000 & .000 & .996 & 1.000 \\
\hline & $\begin{array}{l}\text { Wilks' } \\
\text { Lambda }\end{array}$ & .004 & $3625.444^{b}$ & 2.000 & 26.000 & .000 & .996 & 1.000 \\
\hline \multirow[t]{2}{*}{$\begin{array}{l}\text { Personal } \\
\text { Perception }\end{array}$} & $\begin{array}{l}\text { Pillai's } \\
\text { Trace }\end{array}$ & .949 & 1.877 & 26.000 & 54.000 & .026 & .475 & .963 \\
\hline & $\begin{array}{l}\text { Wilks' } \\
\text { Lambda }\end{array}$ & .220 & $2.263^{b}$ & 26.000 & 52.000 & .006 & .531 & .988 \\
\hline \multirow[t]{2}{*}{ Structured Style } & $\begin{array}{l}\text { Pillai's } \\
\text { Trace }\end{array}$ & .955 & 6.173 & 8.000 & 54.000 & .000 & .478 & 1.000 \\
\hline & $\begin{array}{l}\text { Wilks' } \\
\text { Lambda }\end{array}$ & .203 & $7.924^{b}$ & 8.000 & 52.000 & .000 & .549 & 1.000 \\
\hline \multirow[t]{2}{*}{$\begin{array}{l}\text { Social } \\
\text { Competence }\end{array}$} & $\begin{array}{l}\text { Pillai's } \\
\text { Trace }\end{array}$ & .914 & 3.243 & 14.000 & 54.000 & .001 & .457 & .992 \\
\hline & $\begin{array}{l}\text { Wilks' } \\
\text { Lambda }\end{array}$ & .237 & $3.911^{b}$ & 14.000 & 52.000 & .000 & .513 & .998 \\
\hline \multirow[t]{2}{*}{$\begin{array}{l}\text { Family } \\
\text { Cohesion }\end{array}$} & $\begin{array}{l}\text { Pillai's } \\
\text { Trace }\end{array}$ & .873 & 6.978 & 6.000 & 54.000 & .000 & .437 & .999 \\
\hline & $\begin{array}{l}\text { Wilks' } \\
\text { Lambda }\end{array}$ & .225 & $9.607^{b}$ & 6.000 & 52.000 & .000 & .526 & 1.000 \\
\hline \multirow[t]{2}{*}{$\begin{array}{l}\text { Social } \\
\text { Resources }\end{array}$} & $\begin{array}{l}\text { Pillai's } \\
\text { Trace }\end{array}$ & .441 & 1.910 & 8.000 & 54.000 & .077 & .221 & .739 \\
\hline & $\begin{array}{l}\text { Wilks' } \\
\text { Lambda }\end{array}$ & .594 & $1.933^{b}$ & 8.000 & 52.000 & .074 & .229 & .743 \\
\hline $\begin{array}{l}\text { Social } \\
\text { competence* }\end{array}$ & $\begin{array}{l}\text { Pillai's } \\
\text { Trace }\end{array}$ & .364 & $7.434^{b}$ & 2.000 & 26.000 & .003 & .364 & .913 \\
\hline $\begin{array}{l}\text { Social } \\
\text { Resources }\end{array}$ & $\begin{array}{l}\text { Wilks' } \\
\text { Lambda }\end{array}$ & .636 & $7.434^{b}$ & 2.000 & 26.000 & .003 & .364 & .913 \\
\hline $\begin{array}{l}\text { Family } \\
\text { Cohesion * }\end{array}$ & $\begin{array}{l}\text { Pillai's } \\
\text { Trace }\end{array}$ & .220 & $3.666^{b}$ & 2.000 & 26.000 & .040 & .220 & .623 \\
\hline $\begin{array}{l}\text { Social } \\
\text { Resources }\end{array}$ & $\begin{array}{l}\text { Wilks' } \\
\text { Lambda }\end{array}$ & .780 & $3.666^{b}$ & 2.000 & 26.000 & .040 & .220 & .623 \\
\hline
\end{tabular}

According to the results of the Multivariate Test, it is seen that social resources alone do not influence work engagement and show meaningfulness with the social competence dimension. Similarly, social resources have an impact on engagement to work along with the variable of family adaptation. 


\section{Results and Discussion}

Factor and structural modeling analysis of work engagement resulted that work engagement dimensions reduced to two as dedication and absorption. The vitality dimension of the work engagement lost its statistical significance. As a natural result, we can assume that the related causes of vitality lost their effects. We have linked the vitality dimension of the work engagement to the perception of self and structured style dimensions of resilience. As we argued in Table 1, the insignificance of personal energy may not be caused by biological strength or individual skills; instead, the loss of perception of self and structured style is a resource for loss of vigor to work.

In Afghan culture, the collectivist spirits are materialized and combined, the areas of life that are more or less affected by communal tendency (Iribarne, 2012). Academics of Afghan Universities maintain dedication. Nevertheless, celebrated ideal and day-to-day experience can somehow be the difference of the coexistence of two broad conceptions of what living together means in Afghan territory and daily functioning. From this perspective, we can assume that more individualistic dimensions of resilience from the Western perspective are not affecting work engagement.

Regarding the social self-concept (i.e., academics' perceived acceptance by the community), expectations based on attachment theory (Vervoort et al., 2014) and related research are more straightforward than the perception of self. No studies have examined the connection between the vitality of work engagement and social self-concept.

According to Table 1, we have connected the cause of vitality to a structured style to the individual. As Perception of Self is seemed overly individualistic, so the structured style be. Structured style is about measuring the level of which a person plans and structures their routines(Kelly, Fitzgerald, \& Dooley, 2017; Moljord et al., 2014).

When we analyzed the correlations and MANOVA results, Hypothesis 1 is accepted but to one condition. The correlation matrix (Table 3) shows that all work engagement dimensions are positively related to the social dimension of resilience. However, MANOVA (Table 4) shows that social resources are best to apply with other social dimensions of resilience. Psychological resilience averages (Table 2) of Afghanistan university employees indicate that this capacity is neither magical nor mystical (Masten, 2001).Instead, resilience can be expressed in the sense of community belonging and/or marginalization and structural impediments to emotional and/or social functioning in everyday life (Eggerman \& Panter-Brick, 2010; Miller \& Rasmussen, 2010). Nevertheless, according to the taxonomy model for categorizing social dimensions, work engagement can be associated as an obvious, context-oriented dimension, with social factors as latent, context-oriented dimensions. This result is contradictional to the research that culturally distinct employees work harder and are more likely to achieve adjustment (Ang et al., 2007). So, we can assume that coherent to our research, culture is not a factor but a context for work engagement.

Hypothesis 2 is rejected according to correlation and MANAOVA analysis. The critical component of psychological resilience is the underlying value system that guides, shapes, and gives consistency and meaning to one's cognitions, emotions, and actions. It is thought that the cause of high resiliency is primarily the cultural structure of Afghanistan because values not only have individual aspects but also they are related to context, namely culture (Lopez, 2009).

Families are powerful vehicles of value socialization (Okun, Şen, \& Arun, 2020; Roccas \& Sagiv, 2009, 2017). When the results of the research are examined, it is seen that social resources and family adaptation dimensions, which strengthen the individual's ability to cope with difficulties and which are accepted as individual support resources, have a positive effect on the commitment to 
work. Additionally, in communal societies, reading, and discussion about traditions, members, may learn to consider others, psychological resilience, and interpersonal contact (Kass, 2017).

\section{Conclusion and Recommendations}

This paper has researched effects of resilience on work engagement in a cultural context. Culturally speaking, psychological and social factors of resilience and work engagement are often closely intertwined for persons in some nations(McKay \& Whitehouse, 2015; Sturgeon \& Zautra, 2016).In other words, supportive aspects of one's social world may improve coping problems and overall function for resilience(Connor \& Davidson, 2003). As the research data shows that culturally inclusive community, promoting a national culture helps academics develop psychological resilience.

Psychological Resilience averages of those working in Afghanistan universities are unexpectedly high given the challenges of life. This capacity, which is an unexpected positive result, is now called psychological resilience and can be both process and an outcome variable (Friborg et al., 2005) of social interaction. Meaningful social connections may serve a protective role in resilience by coping with stress(Montoya et al., 2004). According to our analysis of the vitality dimension of work, engagement is found to be not significant. In traditional cultures such as Afghanistan Vertical collectivism (VC) (Triandis, 2004) individuals do not compete with each other as in work engagement. So, our contribution to literature is crucial that work engagement has cultural characteristics.

In our study, it was seen that Afghan university employees had high average psychological resilience and sub-dimensions (3.02-3.21 / 5). Despite the tragic situation, it is in, and high averages confirm that psychological resilience is not due to rare and unique qualities but from the magic of ordinary, the normative sources of the individual's brain and mind, the individual's body, family, relationships and society (Masten, 2001). So, our second contribution to literature come to fore that resilience has more social factors than individual dimensions that psychological processes of resilience have a cultural component.

\section{References}

Ang, S., Van Dyne, L., Koh, C., Ng, K. Y., Templer, K. J., Tay, C., \& Chandrasekar, N. A. (2007). Cultural Intelligence: Its Measurement and Effects on Cultural Judgment and Decision Making, Cultural Adaptation and Task Performance. Management and Organization Review, 3(3), 335-371. https://doi.org/10.1111/j.1740-8784.2007.00082.x

Arun, K., \& Kahraman Gedik, N. (2020). Impact of Asian cultural values upon leadership roles and styles. International Review of Administrative Sciences, 002085232093598. https://doi.org/10.1177/0020852320935982

Arun, K., Şen, C., \& Okun, O. (2020). How does Leadership Effectiveness related to the Context? Paternalistic Leadership on non-financial Performance within a cultural Tightness- Looseness Model? JEEMS Journal of East European Management Studies, 25(3), 503-529. https://doi.org/10.5771/0949-6181-2020-3-503

Baehr, P. (2009). An American University in Afghanistan. Society, 46(1), 9-11. https://doi.org/10.1007/s12115-008-9165-6

Bailey, C., Delbridge, R., Alfes, K., Shantz, A., \& Soane, E. (Eds.). (2013). Employee engagement in theory and practice. Routledge.

Bailey, C., Yeoman, R., Madden, A., Thompson, M., \& Kerridge, G. (2019). A Review of the Empirical Literature on Meaningful Work: Progress and Research Agenda. Human Resource Development Review, 18(1), 83-113. https://doi.org/10.1177/1534484318804653 
Bandura, A. (1997). Self-efficacy: The exercise of control. (pp. ix, 604). W H Freeman/Times Books/ Henry Holt \& Co.

Baumeister, R. F., \& Vohs, K. D. (Eds.). (2007). Encyclopedia of social psychology. Sage Publications.

Begeç, S., \& Arun, K. (2020). The bottleneck of intrapreneurship: Are social positions and held expectations constraints in organizations' entrepreneur process? A conceptual view. Journal of Entrepreneurship in Emerging Economies, ahead-of-print(ahead-of-print). https://doi.org/10.1108/JEEE-08-2019-0120

Bonanno, G. A., \& Diminich, E. D. (2013). Annual Research Review: Positive adjustment to adversity trajectories of minimal-impact resilience and emergent resilience: Annual Research Review Positive adjustment to adversity. Journal of Child Psychology and Psychiatry, 54(4), 378-401. https://doi.org/10.1111/jcpp.12021

Bottrell, D. (2009). Understanding 'Marginal' Perspectives: Towards a Social Theory of Resilience. Qualitative Social Work: Research and Practice, 8(3), 321-339. https://doi.org/10.1177/1473325009337840

Bowles, D. (2014). High engagement work culture: Balancing me and we. Palgrave Macmillan.

Charmes, J. (2019). Dimensions of Resilience in Developing Countries: Informality, Solidarities and Carework. Springer International Publishing. https://doi.org/10.1007/978-3-030-04076-5

Connor, K. M., \& Davidson, J. R. (2003). Development of a new resilience scale: The Connor-Davidson resilience scale (CD-RISC). Depression and Anxiety, 18(2), 76-82. https://doi.org/10.1002/da.10113

Cropanzano, R., \& Mitchell, M. S. (2005). Social Exchange Theory: An Interdisciplinary Review. Journal of Management, 31(6), 874-900. https://doi.org/10.1177/0149206305279602

Davies, A., \& Thomas, R. (2003). Talking Cop: Discourses of Change and Policing Identities. Public Administration, 81(4), 681-699. https://doi.org/10.1111/j.0033-3298.2003.00367.x

de Terte, I., Becker, J., \& Stephens, C. (2009). An Integrated Model for Understanding and Developing Resilience in the Face of Adverse Events. Journal of Pacific Rim Psychology, 3(1), 20-26. https://doi.org/10.1375/prp.3.1.20

Denovan, A., \& Macaskill, A. (2017). Stress, resilience and leisure coping among university students: Applying the broaden-and-build theory. Leisure Studies, 36(6), 852-865. https://doi.org/10.1080/02614367. 2016.1240220

Eggerman, M., \& Panter-Brick, C. (2010). Suffering, hope, and entrapment: Resilience and cultural values in Afghanistan. Social Science \& Medicine, 71(1), 71-83. https://doi.org/10.1016/j. socscimed.2010.03.023

Feldman, R., \& Masalha, S. (2007). The role of culture in moderating the links between early ecological risk and young children's adaptation. Development and Psychopathology, 19(01). https://doi.org/10.1017/ S0954579407070010

Fevzi, F. (2015). AFGANISTAN’DA TÜRK DiLi VE EĞiTiMi. Tehlikedeki Diller Dergisi, 4(6-7), 0-0.

Fletcher, D., \& Sarkar, M. (2013). Psychological resilience: A review and critique of definitions, concepts, and theory. European Psychologist, 18(1), 12-23. https://doi.org/10.1027/1016$9040 / a 000124$

Fredrickson, B. L. (2001). The role of positive emotions in positive psychology: The broaden-and-build theory of positive emotions. American Psychologist, 56(3), 218-226. https://doi.org/10.1037/0003-066X.56.3.218

Friborg, O., Barlaug, D., Martinussen, M., Rosenvinge, J. H., \& Hjemdal, O. (2005). Resilience in relation to personality and intelligence. International Journal of Methods in Psychiatric Research, 14(1), 29-42. https://doi.org/10.1002/mpr.15 
Gagné, M. (Ed.). (2014). The Oxford handbook of work engagement, motivation, and selfdetermination theory. Oxford University Press.

González-Romá, V., Schaufeli, W. B., Bakker, A. B., \& Lloret, S. (2006). Burnout and work engagement: Independent factors or opposite poles? Journal of Vocational Behavior, 68(1), 165-174. https://doi.org/10.1016/j.jvb.2005.01.003

Harrington, A. (2008). The cure within: A history of mind-body medicine (1st ed). W.W. Norton.

Haslam, S. A., O’Brien, A., Jetten, J., Vormedal, K., \& Penna, S. (2005). Taking the strain: Social identity, social support, and the experience of stress. British Journal of Social Psychology, 44(3), 355-370. https://doi.org/10.1348/014466605X37468

Iribarne, P. d'. (2012). Managing corporate values in diverse national cultures: The challenge of differences. Routledge.

Jensen, G. (2019). Rethinking Legal Education In Afghanistan: The Law Program At The American University Of Afghanistan. Stanford Journal of International Law, 33.

Johns, G. (2006). The essential impact of context on organizational behavior. Academy of Management Review, 31(2), 386-408. https://doi.org/10/cz58vr

Kahn, W. A. (1990). Psychological Conditions Of Personal Engagement And Disengagement At Work. Academy of Management Journal, 33(4), 692-724. https://doi.org/10.2307/256287

Kashima, Y. (2013). Culture comparison and culture priming: A critical analysis. In Understanding Culture (pp. 67-91). Psychology Press.

Kass, J. D. (2017). Prologue to an Experiment in Higher Education: Mentoring Psychospiritual Maturation, Breaking Humanity's Chain of Pain. In J. D. Kass, A Person-Centered Approach to Psychospiritual Maturation (pp. 3-20). Springer International Publishing. https://doi.org/10.1007/978-3-319-57919-1_1

Kelly, Y., Fitzgerald, A., \& Dooley, B. (2017). Validation of the Resilience Scale for Adolescents (READ) in Ireland: A multi-group analysis: Validation of READ with Adolescents in Ireland. International Journal of Methods in Psychiatric Research, 26(2), e1506. https://doi.org/10.1002/mpr.1506

Killgore, W. D. S., Taylor, E. C., Cloonan, S. A., \& Dailey, N. S. (2020). Psychological Resilience During the COVID-19 Lockdown. Psychiatry Research, 113216. https://doi.org/10.1016/j.psychres.2020.113216

Knight, C., Patterson, M., \& Dawson, J. (2017). Building work engagement: A systematic review and meta-analysis investigating the effectiveness of work engagement interventions: Effectiveness of Work Engagement Interventions. Journal of Organizational Behavior, 38(6), 792-812. https://doi.org/10.1002/job.2167

Lee, J. H., Nam, S. K., Kim, A.-R., Kim, B., Lee, M. Y., \& Lee, S. M. (2013). Resilience: A Meta-Analytic Approach. Journal of Counseling \& Development, 91(3), 269-279. https://doi.org/10.1002/j.1556-6676.2013.00095.x

Linnenluecke, M. K. (2017). Resilience in Business and Management Research: A Review of Influential Publications and a Research Agenda: Resilience in Business and Management Research. International Journal of Management Reviews, 19(1), 4-30. https://doi.org/10.1111/ijmr.12076

Lopez, S. J. (Ed.). (2009). Encyclopedia of positive psychology. Wiley-Blackwell.

Luthans, F. (2002). The need for and meaning of positive organizational behavior. Journal of Organizational Behavior, 23(6), 695-706. https://doi.org/10.1002/job.165 
Masten, A. S. (2001). Ordinary magic: Resilience processes in development. American Psychologist, 56(3), 227-238. https://doi.org/10.1037/0003-066X.56.3.227

McKay, R., \& Whitehouse, H. (2015). Religion and morality. Psychological Bulletin, 141(2), 447. https://doi.org/10.1037/a0038455

McLellan, T., Rotella, B., Grote-Garcia, S. A., Proctor, S. L., Patanella, D., Block, M., Stewart, L. S., Pham, A. V., Carlson, J. S., Kibler, J., Krohn, K. R., Bender, S. L., Pham, A. V., Carlson, J. S., Bannon, R. S., Chang, M. Y., Dean, R. S., Mitchell, A. D., King, H., ... Wilkinson, L. A. (2011). Social Learning Theory. In S. Goldstein \& J. A. Naglieri (Eds.), Encyclopedia of Child Behavior and Development (pp. 1396-1397). Springer US. https://doi.org/10.1007/978-0-387-79061-9_2695

Meyer, J., Gagné, M., \& Parfyonova, N. (2010). Toward an evidence-based model of engagement: What we can learn from motivation and commitment research. 62-73.

Meyer, J. P. (2014). Employee commitment, motivation, and engagement: Exploring the links. In The Oxford handbook of work engagement, motivation, and self-determination theory (pp. 33-49). Oxford University Press.

Miller, K. E., \& Rasmussen, A. (2010). War exposure, daily stressors, and mental health in conflict and post-conflict settings: Bridging the divide between trauma-focused and psychosocial frameworks. Social Science \& Medicine (1982), 70(1), 7-16. https://doi.org/10.1016/j.socscimed.2009.09.029

Moljord, I. E. O., Moksnes, U. K., Espnes, G. A., Hjemdal, O., \& Eriksen, L. (2014). Physical activity, resilience, and depressive symptoms in adolescence. Mental Health and Physical Activity, 7(2), 79-85. https://doi.org/10.1016/j.mhpa.2014.04.001

Montoya, P., Larbig, W., Braun, C., Preissl, H., \& Birbaumer, N. (2004). Influence of social support and emotional context on pain processing and magnetic brain responses in fibromyalgia. Arthritis \& Rheumatism, 50(12), 4035-4044. https://doi.org/10.1002/art.20660

Nakkula, M. J., Foster, K. C., Mannes, M., \& Bolstrom, S. (2010). Building Healthy Communities for Positive Youth Development. Springer Sciencet Business Media, LLC. http://site.ebrary.com/lib/alltitles/ docDetail.action?doclD=10404553

Okun, O., Şen, C., \& Arun, K. (2020). How Do Paternalistic Leader Behaviors Shape Xenophobia in Business Life? International Journal of Organizational Leadership, 9(1), 1-19. https://doi.org/10.33844/ijol.2020.60487

Ouweneel, E., Le Blanc, P. M., \& Schaufeli, W. B. (2013). Do-it-yourself: An online positive psychology intervention to promote positive emotions, self-efficacy, and engagement at work. Career Development International, 18(2), 173-195. https://doi.org/10.1108/CDI-10-2012-0102

Park, S., Kim, J., Park, J., \& Lim, D. H. (2018). Work Engagement in Nonprofit Organizations: A Conceptual Model. Human Resource Development Review, 17(1), 5-33. https://doi.org/10.1177/1534484317750993

Roccas, S., \& Sagiv, L. (2009). Values. In S. J. Lopez (Ed.), Encyclopedia of positive psychology (pp. 1002-1006). Wiley-Blackwell.

Roccas, S., \& Sagiv, L. (Eds.). (2017). Values and Behavior: Taking a Cross Cultural Perspective. Springer International Publishing. https://doi.org/10.1007/978-3-319-56352-7

Rutter, M. (2006). Implications of Resilience Concepts for Scientific Understanding. Annals of the New York Academy of Sciences, 1094(1), 1-12. https://doi.org/10.1196/annals.1376.002

Rutter, Michael. (1987). Psychosocial resilience and protective mechanisms. American Journal of Orthopsychiatry, 57(3), 316-331. https://doi.org/10.1111/j.1939-0025.1987.tb03541.x

Saks, A. M. (2006). Antecedents and consequences of employee engagement. Journal of Managerial Psychology, 21(7), 600-619. https://doi.org/10.1108/02683940610690169

Schaufeli, W. B., Bakker, A. B., \& Salanova, M. (2006). The Measurement of Work Engagement With a Short Questionnaire: A Cross-National Study. Educational and Psychological Measurement, 66(4), 701-716. https://doi.org/10.1177/0013164405282471 
Schaufeli, W. B., Bakker, A. B., \& Van Rhenen, W. (2009). How changes in job demands and resources predict burnout, work engagement, and sickness absenteeism. Journal of Organizational Behavior, 30(7), 893-917. https://doi.org/10.1002/job.595

Schaufeli, W. B., Salanova, M., González-romá, V., \& Bakker, A. B. (2002). The Measurement of Engagement and Burnout: A Two Sample Confirmatory Factor Analytic Approach. Journal of Happiness Studies, 3(1), 71-92. https://doi.org/10.1023/A:1015630930326

Schwartz, S. (2009). Culture matters: National value cultures, sources and consequences. In Understanding Culture: Theory, Research and Application (pp. 127-150).

Sheldon, K. (2002). The self-concordance model of healthy goal-striving: When personal goals correctly represent the pe. Engineering Letters.

Sturgeon, J. A., \& Zautra, A. J. (2016). Social pain and physical pain: Shared paths to resilience. Pain Management, 6(1), 63-74. https://doi.org/10.2217/pmt.15.56

Swanberg, J. E., McKechnie, S. P., Ojha, M. U., \& James, J. B. (2011). Schedule control, supervisor support and work engagement: A winning combination for workers in hourly jobs? Journal of Vocational Behavior, 79(3), 613-624. https://doi.org/10.1016/j.jvb.2011.04.012

Theron, L., Ann Cameron, C., Didkowsky, N., Lau, C., Liebenberg, L., \& Ungar, M. (2011). A “Day in the Lives" of Four Resilient Youths: Cultural Roots of Resilience. Youth \& Society, 43(3), 799-818. https://doi.org/10.1177/0044118X11402853

Triandis, H. C. (2004). The Many Dimensions of Culture. The Academy of Management Executive (1993-2005), 18(1), 88-93. JSTOR.

Tsui, A. S., Nifadkar, S. S., \& Ou, A. Y. (2009). Nagging problems and modest solutions in cross-cultural research: Illustrations from organizational behavior literature. In Understanding culture: Theory, research, and application (pp. 163-186). Psychology Press.

Tsvetkova, N. (2017). Americanisation, sovietisation, and resistance at Kabul University: Limits of the educational reforms. History of Education, 46(3), 343-365. https://doi.org/10.1080/0046760X.2016.1246676

Ungar, M. (2011). The social ecology of resilience: Addressing contextual and cultural ambiguity of a nascent construct. The American Journal of Orthopsychiatry, 81(1), 1-17. https://doi.org/10.1111/j.1939-0025.2010.01067.x

Vella, S.-L. C., \& Pai, N. B. (2019). A theoretical review of psychological resilience: Defining resilience and resilience research over the decades. https://doi.org/10/ggr6x2

Vervoort, E., Bosmans, G., Doumen, S., Minnis, H., \& Verschueren, K. (2014). Perceptions of self, significant others, and teacher-child relationships in indiscriminately friendly children. Research in Developmental Disabilities, 35(11), 2802-2811. https://doi.org/10.1016/j.ridd.2014.07.004

Wachs, T. D. (2012). Poverty, Child Risk, and Resilience in Developing Countries. In J. Boyden \& M. Bourdillon (Eds.), Childhood Poverty (pp. 148-165). Palgrave Macmillan UK. https://doi.org/10.1057/9780230362796_10

Zolkoski, S. M., \& Bullock, L. M. (2012). Resilience in children and youth: A review. Children and Youth Services Review, 34(12), 2295-2303. https://doi.org/10.1016/j.childyouth.2012.08.009

Received: March 10, 2020

Revisions Received: Aug 19, 2020 